\title{
SIKAP RUMAH TANGGA TERHADAP KOMODITAS CABAI KERING (APLIKASI PENDEKATAN THEORY OF PLANNED BEHAVIOR)
}

\author{
Achmad Fachruddin ${ }^{1)}$, Muhammad Firdaus ${ }^{2)}$ dan Netti Tinaprilla ${ }^{3)}$ \\ ${ }^{1,3)}$ Departemen Agribisnis, Fakultas Ekonomi dan Manajemen,Institut Pertanian Bogor \\ ${ }^{2)}$ Departemen Ilmu Ekonomi, Fakultas Ekonomi dan Manajemen,Institut Pertanian Bogor \\ ${ }^{1)}$ fachru.dreamer@gmail.com
}

\begin{abstract}
Dried chillies arepotential to substitute fresh chillies when the price of fresh chillies significantly increases, and its purchases were expected to determine by the household consumer's attitude. The aims of this researchare 1) to examine the household attitudes on dried chilies purchasing bythe Theory of Planned Behavior approach, 2) to determine the determinant factors ofdried chilli buying intention, and 3) to estimate the cross-elasticity of dried chili againsts fresh chilli. The results showed that household consumer attitude towards the purchase of dried chillies, in term of subjective norms,perceived behavioral control, and purchase intention, are in medium category. The determinant factors on purchase intention of dried chilies $(\alpha=10$ percent) are the subjective norms, attitudes towards the purchase of dried chilies, and household income per month. The dried chilli cross-elasticity valueis very inelastic (0.069). Due to that, the policy implications in encouraging the dried chilli purchasing are the socialization of the dried chilli's benefits and sustain the avaibility of dried chillies in traditional markets.
\end{abstract}

Keyword(s): dried chilli, planned behavior, household income.

\begin{abstract}
ABSTRAK
Cabai kering diduga memiliki potensi dalam mensubstitusi cabai segar saat terjadi peningkatan harga yang signifikan. Sikap konsumen rumah tangga menjadi salah satu faktor penentu dalam pembelian cabai kering.Tujuan penelitian ini yaitu, 1) mengkaji sikap rumah tangga terhadap cabai kering dengan pendekatan Theory of Planned Behavior, 2) menentukan faktor yang berpengaruh terhadap niat beli cabai kering, 3) mengestimasi nilai elastisitas silang cabai kering terhadap cabai segar. Hasil penelitian menunjukkan bahwa sikap konsumen rumah tangga terhadap pembelian cabai kering, norma subjektif, persepsi pengendalian perilaku, dan niat beli berada pada kategori sedang. Faktor yang berpengaruh nyataterhadap niat beli cabai kering ( $\alpha=10$ persen) yaitu norma subjektif, sikap terhadap pembelian cabai kering, dan pendapatan rumah tangga per bulan. Nilai elastisitas silang cabai kering terhadap cabai segarsangat inelastis $(0,069)$.Implikasi kebijakan untuk mendorong pembelian cabai kering adalah sosialisasi tentang manfaat komoditas cabai kering dan menjaga ketersediaan cabai kering pada pasar tradisional.
\end{abstract}

Kata Kunci: cabai kering, planned behavior, pendapatan rumah tangga.

\section{PENDAHULUAN}

Pemanfaatan komoditas cabai terbagi dua, yaitu cabai konsumsi dan cabai industri. Cabai konsumsi merupakan cabai yang dimanfaatkan oleh konsumen akhir dalam keadaan segar. Cabai segar juga digunakan oleh Usaha Mikro Kecil dan Menengah (UMKM) seperti pe- 
dagang cabai giling. Sedangkan cabai industri merupakan bentuk olahan dari cabai yang dimanfaatkan sebagai bahan baku oleh pelaku industri. Cabai industri terdiri atas cabai kering (cabai utuh dengan kadar air 14 persen), cabai saus, cabai bubuk kasar, dan cabai bubuk halus. Berdasarkan survei pendahuluan, cabai kering sudah mulai digunakan oleh UMKM sebagai bahan substitusi cabai segar sejak lima tahun terakhir.

Cabai kering diduga dapat menjadi substitusi cabai konsumsi karena bentuknya utuh seperti cabai segar dan dapat disegarkan kembali dengan merendamnya dalam air hangat. Konsumen rumah tangga dapat menggunakan cabai kering terutama saat terjadi peningkatan harga cabai segar yang signifikan. Peningkatan harga cabai yang signifikan sangat mungkin terjadi karena komoditas cabai memiliki koefisien keragaman harga dan disparitas harga antar wilayah yang tinggi. Komoditas cabai memberikan kontribusi 0,3 persen pada inflasi tahun 2013 (BI, 2013).

Koefisien keragaman harga cabai pada September 2012 sampai dengan September 2013 sebesar 22,42 persen dan disparitas harga sebesar 34,45 persen (Kemendag, 2013). Pada tingkat konsumen akhir harga rata-rata bulanan tertinggi untuk cabai merah biasa yaitu Rp 36.998 (Pusdatin 2013). Jika dilihat secara geografis, harga rata-rata cabai di ibukota provinsi di Pulau Jawa tidak melebihi Rp 30.000, sedangkan pada pulau lainnya harga rata-rata dapat mencapai kisaran Rp 40.000-42.000. Harga rata-rata bulanan tertinggi cabai merah biasa terjadi di Maluku Utara dan Bandung yaitu sebesar Rp 64.059 dan Rp 61.381.

Kelebihan permintaan cabai terutama saat gagal panen atau hari raya, merupakan determinan kondisi peningkatan harga yang signifikan. Permintaan cabai mengalami peningkatan sebab cabai salah satu kebutuhan pokok masyarakat Indonesia khususnya sebagai bumbu masak. Konsumsi cabai per kapita per tahun untuk cabai merah, cabai hijau, dan cabai rawit berturut-turut yaitu 1,596 $\mathrm{kg}, 1,648 \mathrm{~kg}$, dan 0,213 kg, mengalami peningkatan dari tahun 2011 (BPS, 2012). Sedangkan penawaran mengalami penurunan akibat produksi cabai rentan mengalami gangguan hama dan penyakit, serta anomali iklim.

Dirjen Hortikultura menyatakan bahwa cabai kering sudah mulai dikonsumsi oleh rumah tangga, khususnya kelas pendapatan menengah ke atas ${ }^{1}$. Informasi tersebut menunjukkan bahwa cabai kering memiliki prospek untuk dijadikan substitusi cabai segar oleh konsumen rumah tangga.

Prospek substitusi cabai kering terhadap cabai segar berkaitan erat dengan sikap konsumen rumah tangga terhadap cabai kering. Sikap konsumen merupakan salah satu karakteristik psikologi konsumen yang berpengaruh terhadap proses pembelian. (Engel, 1994; Kotler dan Amstrong, 2006). Salah satu model sikap yang dapat digunakan untuk mengukur sikap terhadap sebuah produk baru, yaitu Theory Planned of Behavior

\footnotetext{
${ }^{1}$ http://www.agrina-

online.com/redesign2.php?rid=20\&aid=3834
} 
(TPB). Pada model tersebut, sikap terhadap pembelian dapat mempengaruhi niat beli produk. Niat beli merupakan faktor yang mendorong pembelian produk (Ajzen, 1991). Dua faktor lain dalam model TPB yang mempengaruhi niat beli sebuah produk adalah norma subjektif dan persepsi pengendalian perilaku (Lampiran 1). Pengaruh ketiga variabel tersebut terhadap niat beli dapat berbeda antara satu produk dengan produk lainnya (Dewi dan Yusalina (2011); Putri (2012); Izdihar (2013); Awwaliyah (2013)).

Sikap konsumen terhadap cabai kering diduga dipengaruhi oleh jumlah pendapatan per bulan. Berdasarkan informasi di atas, rumah tangga dengan pendapatan menengah ke atas adalah kelompok yang sudah mulai menggunakan cabai kering. Jika cabai kering diasumsikan sebagai barang inferior, maka pembelian cabai kering seharusnya lebih banyak dilakukan oleh konsumen rumah tangga dengan pendapatan menengah ke bawah.

Harga cabai kering di pasar tradisional lokal berkisar $\mathrm{Rp} 60.000$ 70.000 per kg. Estimasi elastisitas silang terhadap cabai segar dapat memperkaya penjelasan tentang prospek pembelian cabai kering oleh konsumen rumah tangga.

Berdasarkan pemaparan di atas, pertanyaan yang hendak dijawab yaitu:

1. Bagaimana sikap konsumen rumah tangga terhadap cabai kering dengan pendekatan Theory of Planned Behavior?

2. Faktor apakah yang berpengaruh terhadap niat beli cabai kering?
3. Berapa elastisitas silang permintaan cabai kering terhadap cabai segar?

Sehingga tujuan penelitian yaitu:

1. Mengkaji sikap konsumen rumah tangga terhadap cabai kering dengan pendekatan Theory of Planned Behavior.

2. Menentukan faktor yang berpengaruh terhadap niat beli cabai kering.

3. Mengestimasi nilai elastisitas silang permintaan cabai kering terhadap cabai segar.

\section{METODOLOGI}

Lokasi penelitian adalah Kota dan Kabupaten Bogor, dipilih secara purposive. Penelitian dilakukan pada bulan Januari 2014. Metode pengumpulan data dalam bentuk survei melalui kuesioner.

Sampel ibu rumah tangga yang disertakan sebanyak 30 orang yang terbagi ke dalam tiga kelas pendapatan per bulan, yaitu kelas 1 kurang dari Rp $\quad 5.000 .000 \quad(\mathrm{n}=11), \quad$ kelas 2 Rp 5.000.000 - 10.000.000 ( $\mathrm{n}=10)$, dan kelas 3 lebih dari Rp 10.000.000 (n=9) (Lampiran 2).

Analisis data yang digunakan untuk menjelaskan sikap dengan pendekatan TPB adalah analisis deskriptif. Model sikap TPB dipilih berdasarkan karakteristik produk yang masih baru. Model sikap yang umumnya digunakan dalam pengukuran sikap yaitu Multiatribut Fishbein. Namun model sikap tersebut digunakan untuk mengukur sikap konsumen yang sudah menggunakan produk (Nurmalina et al. 2012, Sari. 2013). Analisis regresi berganda digunakan untuk menentukan variabel yang berpengaruh terhadap niat beli. 
Pengukuran setiap komponen model TPB menggunakan skala Likert 1 sampai 4. Pemberian skor pada variabel sikap terhadap pembelian cabai kering (ATB), norma subjektif (SN), dan persepsi pengendalian perilaku (PBC) dilakukan dengan cara menjumlahkan perkalian kedua komponen pada masing-masing variabel, sesuai dengan model TPB.

Berikut rumus mengukur sikap terhadap pembelian cabai kering (ATB):

$$
\text { ATB }=\sum_{i=1}^{n} b_{i} e_{i}
$$

$$
\begin{aligned}
\text { ATB }= & \text { penilaian individu terhadap positif atau } \\
& \text { negatifnya konsekuensi pembelian cabai kering } \\
b_{i}= & \text { kepercayaan bahwa pembelian cabai kering } \\
& \text { mengarahkan pada konsekuensi tertentu } \\
& \text { (behavioral belief) } \\
e_{i}= & \text { evaluasi terhadap konsekuensi dari pembelian } \\
& \text { cabai kering (outcome evaluation) }
\end{aligned}
$$

Behavioral belief dan outcome evaluation masing-masing diukur dengan lima pernyataan terkait kon-sekuensi daya tahan (K1), kualitas sambal yang dihasilkan (K2), harga cabai kering (K3), kepraktisan peng-gunaan cabai kering (K4), dan volume cabai kering (K5). Norma subjektif (SN) dijelaskan oleh rumus berikut:

$$
S N=\sum_{i=1}^{n} b_{i} m_{i}
$$

\footnotetext{
$\mathrm{SN}=$ persepsi individu tentang tekanan sosial di sekitarnya untuk melakukan atau tidak melakukan pembelian cabai kering

$b_{i} \quad=$ kepercayaan normatif referensi terhadap pembelian cabai kering (normative belief)

$m_{i} \quad=$ motivasi untuk mengikuti sejumlah referensi (motivation to comply)
}

Normative belief dan motivation to comply masing-masing diukur dengan empat pernyataan terkait referensi komunitas ibu rumah tangga (R1), acara masak di televisi (R2), pedagang sayur (R3), dan iklan layanan masyarakat (R4). Persepsi pengendalian perilaku (PBC) dijelaskan oleh rumus berikut:

$$
P B C=\sum_{i=1}^{n} C_{i} P_{i}
$$

\footnotetext{
PBC = tingkat kepercayaan seseorang tentang kesempatan atau kekuatan yang dimilikinya untuk melakukan pembelian cabai kering

$c_{i} \quad=$ keyakinan individu bahwa ia mampu mengendalikan pembelian cabai kering (control belief strength)

$p_{i} \quad=$ Keyakinan individu akan adanya hambatan atau dukungan dalam pembelian cabai kering (power of control factor)
}

Control belief strength dan power of control factor diukur dengan dua pertanyaan terkait dengan faktor harga yang mahal (F1) dan ketersediaan cabai kering (F2).

Variabel niat beli cabai kering (BI) diukur menggunakan empat pernyataan, yaitu niat beli cabai kering pekan ini, niat beli cabai kering bulan ini, niat beli cabai kering jika cabai kering tersedia di pasar terdekat, dan niat beli cabai kering jika harga cabai segar sangat mahal. Penjumlahan dari skor tiap pernyataan merupakan total skor niat beli produk cabai kering.

Masing-masing variabel TPB dikategorikan ke dalam tiga kelompok, yaitu rendah, sedang, dan tinggi (Tabel 1), ditentukan dengan menggunakan rumus berikut:

$$
I K=\frac{\text { skor maks }- \text { skor } \min }{\sum \text { kategori }}
$$


Tabel 1. Interval Kelas (IK) dan Skor Variabel TPB

\begin{tabular}{lrrr}
\hline \multirow{2}{*}{ Variabel } & \multicolumn{3}{c}{ Interval kelas dan skor } \\
\cline { 2 - 4 } & Rendah & Sedang & \multicolumn{1}{c}{ Tinggi } \\
\hline Sikap terhadap pembelian & $5-30$ & $31-56$ & $57-80$ \\
Norma subjektif & $4-24$ & $25-45$ & $46-64$ \\
Persepsi pengendalian perilaku & $2-12$ & $13-23$ & $24-32$ \\
Niat & $4-8$ & $9-12$ & $13-16$ \\
\hline
\end{tabular}

Masing-masing variabel TPB dikategorikan ke dalam tiga kelompok, yaitu rendah, sedang, dan tinggi (Tabel 1), ditentukan dengan menggunakan rumus berikut:

$$
I K=\frac{\text { skor maks }- \text { skor } \min }{\sum \text { kategori }}
$$

Analisis regresi linier berganda diestimasi dengan metode Ordinary Least Squares (OLS). Beberapa asumsi yang harus dipenuhi (Thomas 1997), yaitu:

1. $\mathrm{E}\left(\varepsilon_{i}\right)=0$ untuk semua $i$, nilai harapan residual sama dengan nol untuk semua amatan

2. $\operatorname{Var}\left(\varepsilon_{i}\right)=\mathrm{E}\left(\varepsilon_{i}^{2}\right)=\sigma^{2}=$ konstan untuk semua $i$, varians konstan (homoskedasitisitas)

3. $\operatorname{Cov}\left(\varepsilon_{i}, \varepsilon_{i}\right)=\mathrm{E}\left(\varepsilon_{i}, \varepsilon_{i}\right)=0 \quad$ untuk semua $i \neq j$, tidak ada autokorelasi antar residual

4. Residual $\left(\varepsilon_{i}\right)$ menyebar normal

5. Tidak terjadi multikolinier antar variabel independen

Fungsi niat beli cabai kering adalah sebagai berikut:

$$
Y_{i}=\beta_{0}+\beta_{1} X_{1}+\beta_{2} X_{2}+\beta_{3} X_{3}+\beta_{4} X_{4}+\varepsilon_{i}
$$

Keterangan:

$Y=$ skor niat beli cabai kering

$\beta_{0}=$ intersep

$\beta=$ parameter dugaan $(1-4)$

$X_{I}=$ skor sikap terhadap pembelian cabai kering

$X_{2}=$ skor norma subjektif
$X_{3}=$ skor persepsi pengendalian perilaku

$X_{4}=$ pendapatan per bulan (juta)

$\varepsilon_{i} \quad=$ galat

Elastisitas permintaan silang titik cabai segar terhadap cabai kering, diukur melalui persamaan berikut (Salvatore, 2005):

Keterangan:

$$
\mathrm{E}_{x y}=\frac{\Delta Q_{x} / Q_{x}}{\Delta P_{y} / P_{y}}=\frac{\Delta Q_{x}}{\Delta P_{y}} \times \frac{P_{y}}{Q_{x}}
$$

$\mathrm{E}_{x y}=$ elastisitas silang harga cabai segar terhadap cabai kering

$Q_{x} \quad=$ jumlah cabai kering yang diminta $(\mathrm{kg})$

$\mathrm{P}_{\mathrm{y}} \quad=$ harga cabai segar (rupiah)

Nilai elastisitas dihitung pada dua titik harga cabai segar, yaitu saat terjadi permintaan cabai kering dan sebelum terjadi permintaan cabai kering.

\section{HASIL DAN PEMBAHASAN}

Sikap Rumah Tangga Terhadap Cabai Kering (TPB)

\section{Sikap Terhadap Pembelian (ATB)}

Sikap konsumen rumah tangga terhadap pembelian cabai kering (ATB) secara keseluruhan berada dalam kategori sedang (31-56), yaitu 39,57 (Tabel 2). Skor sikap tertinggi sebesar 61 dan skor terendah sebesar 17. Responden yang memiliki skor sikap tertinggi adalah rumah tangga yang telah memiliki pengetahuan tentang cabai kering. 
Skor sikap pada rumah tangga pendapatan kelas $1(43,18)$ lebih tinggi dibandingkan dengan pendapatan kelas 2 $(36,90)$ dan pendapatan kelas $3(38,11)$. Hal tersebut menunjukkan bahwa rumah tangga dengan pendapatan kurang dari Rp 5.000.000 memiliki penilaian yang lebih tinggi bahwa sebaiknya mereka membeli cabai kering.

Ketiga rumah tangga memberikan penilaian yang berbeda pada konsekuensi harga cabai kering $\left(\mathrm{ATB}_{3}\right)$. Rumah tangga pendapatan kelas 1 meyakini bahwa harga cabai kering relatif lebih murah dari cabai segar dan menilai bahwa harga cabai yang murah merupakan hal yang penting. Hal tersebut membuat konsekuensi harga cabai kering memberikan kontribusi terbesar pada sikap terhadap pembelian cabai kering $(12,09)$. Sebaliknya pada rumah tangga pendapatan kelas 2 dan pendapatan kelas 3 menilai bahwa kualitas cabai lebih penting dibanding-kan dengan harganya. Kedua kelas pendapatan meyakini bahwa cabai kering lebih mahal dibandingkan dengan cabai segar. Hal tersebut membuat konse-kuensi harga cabai kering memberikan kontribusi terkecil pada skor sikap terhadap pembelian cabai kering (5,40 dan 6,33).
Ketiga kelas rumah tangga relatif memiliki sikap yang sama pada konsekuensi manfaat daya tahan produk $\left(\mathrm{ATB}_{1}\right)$, kualitas sambal yang dihasilkan $\left(\mathrm{ATB}_{2}\right)$, kepraktisan cara menggunakan $\left(\mathrm{ATB}_{4}\right)$, dan perbandingan volume dengan cabai segar $\left(\mathrm{ATB}_{5}\right)$. Dari keempat konsekuensi tersebut, manfaat daya tahan produk memberikan skor terbesar sikap terhadap pembelian pada ketiga kelas pendapatan $(8,64 ; 8,80$; $9,56)$. Konsumen rumah tangga memiliki keyakinan yang sama bahwa cabai kering dapat disimpan untuk waktu yang lama (lebih dari 1 tahun). Namun rumah tangga pendapatan kelas 2 dan 3 relatif tidak memiliki keinginan menyimpan cabai dalam waktu yang lama. Rumah tangga yang ingin menyimpan cabai yang kering umumnya adalah yang memiliki pengetahuan tentang peman-faatan cabai kering.

Dalam konsekuensi kualitas sambal yang dihasilkan $\left(\mathrm{ATB}_{2}\right)$, konsumen rumahtangga umumnya meyakini bahwa penggunaan cabai kering tetap menghasilkan tingkat kepedasan yang sama, namun menurunkan kualitas kesegaran sambal. Sehingga rumah tangga yang terbiasa mengggunakan cabai segar memiliki sikap yang rendah terhadap cabai kering.

Tabel 2. Sikap Terhadap Pembelian Cabai Kering

\begin{tabular}{lcccccc}
\hline \multicolumn{1}{c}{ Rumah Tangga } & $\mathbf{A T B}_{\mathbf{1}}$ & $\mathbf{A T B}_{\mathbf{2}}$ & $\mathbf{A T B}_{\mathbf{3}}$ & $\mathbf{A T B}_{\mathbf{4}}$ & $\mathbf{A T B}_{\mathbf{5}}$ & $\mathbf{A T B}_{\text {total }}$ \\
\hline Kelas $1(\mathrm{n}=11)$ & 8,64 & 7,36 & 12,09 & 6,36 & 8,73 & 43,18 \\
Kelas 2 $(\mathrm{n}=10)$ & 8,80 & 8,10 & 5,40 & 6,40 & 8,20 & 36,90 \\
Kelas 3 $(\mathrm{n}=9)$ & 9,56 & 7,00 & 6,33 & 7,33 & 7,89 & 38,11 \\
\hline Total responden $(\mathrm{n}=30)$ & 8,97 & 7,50 & 8,13 & 6,67 & 8,30 & 39,57 \\
\hline Sumber: Data primer $(2014)$ & & & & & &
\end{tabular}


Adapun rumah tangga yang mempunyai pengalaman dalam mengkonsumsi cabai kering menyebutkan bahwa cabai kering memiliki kelebihan dalam mengentalkan sambal dan sebagai bumbu pada jenis masakan rendang, kari, dan campuran santan. Hal tersebut menunjukkan bahwa responden yang memiliki pengetahuan tentang keunggulan cabai kering memberikan pengaruh yang positif terhadap pembelian cabai kering.

Kebiasaan rumah tangga yang berbeda dalam membuat sambal mempengaruhi penilaian pada konsekuensi kepraktisan cara menggunakan $\left(\mathrm{ATB}_{4}\right)$. Rumah tangga yang terbiasa membuat sambal dengan menggunakan blender, menganggap bahwa cabai kering sama dengan cabai segar dalam aspek kepraktisan penggunannya. Namun rumah tangga yang menggunakan ulekan manual, menilai bahwa cabai kering tidak praktis karena sulit untuk diulek.

Konsekuensi volume cabai kering yang lebih banyak dari cabai segar pada jumlah (massa) yang sama $\left(\mathrm{ATB}_{5}\right)$, cukup memberikan kontribusi positif pada sikap terhadap pembelian. Namun kontribusi tersebut lebih rendah di-bandingkan kontribusi penilaian manfaat daya tahan cabai kering yang telah dibahas di atas. Hal tersebut menun-jukkan konsekuensi daya tahan produk lebih penting dari konsekuensi volume produk.

\section{Norma Subjektif}

Secara umum norma subjektif (SN) terhadap pembelian cabai kering berada pada kategori rendah, yaitu 17,73 (Tabel 3). Seperti sikap terhadap pembelian, rumah tangga pendapatan kelas 1 memiliki norma subjektif yang lebih besar $(21,36)$ dari norma subjektif pendapatan kelas $2(16,50)$ dan kelas 3 $(14,67)$.

Hal tersebut menunjukkan bahwa rumah tangga tidak merasakan adanya dorongan dari lingkungan sosial (empat referensi) untuk membeli cabai kering.

Seluruh responden menyatakan bahwa hampir tidak ada saran atau promosi dari keempat referensi untuk membbeli cabai kering (komunitas ibu rumah tangga, acara masak di televisi, pedagang sayuran atau supermarket langganan, iklan layanan masyarakat). Adapun skor norma subjektif pada setiap referensi (Tabel 3) dapat bernilai lebih dari 3 disebabkan oleh komponen motivasi untuk mematuhi (motivation to comply).

Tabel 3. Norma Subjektif Terhadap Pembelian Cabai Kering

\begin{tabular}{llllll}
\hline \multicolumn{1}{c}{ Rumah Tangga } & $\mathbf{S N}_{\mathbf{1}}$ & $\mathbf{S N}_{\mathbf{2}}$ & $\mathbf{S N}_{\mathbf{3}}$ & $\mathbf{S N}_{\mathbf{4}}$ & $\mathbf{S N}_{\text {total }}$ \\
\hline Kelas 1 $(\mathrm{n}=11)$ & 6,09 & 5,27 & 5,00 & 5,00 & 21,36 \\
Kelas 2 $(\mathrm{n}=10)$ & 3,30 & 5,20 & 4,10 & 3,90 & 16,50 \\
Kelas 3 $(\mathrm{n}=9)$ & 3,33 & 3,67 & 4,67 & 3,00 & 14,67 \\
\hline Total $(\mathrm{n}=30)$ & 4,33 & 4,77 & 4,60 & 4,03 & 17,73 \\
\hline Sumber: Data primer (2014) & & & & &
\end{tabular}


Tiga kelas pendapatan rumah tangga memiliki kecenderungan yang berbeda dalam motivasi mematuhi referensi tertentu untuk membeli cabai kering. Rumah tangga pendapatan kelas 1 memiliki motivasi mematuhi terbesar terhadap referensi komunitas ibu rumah tangga $\left(\mathrm{SN}_{1}\right)$. Rumah tangga pendapatan kelas 2 memiliki motivasi mematuhi terbesar terhadap referensi acara masakmemasak di televisi $\left(\mathrm{SN}_{2}\right)$. Namun motivasi menggunakan cabai kering yang dilakukan karena adanya promosi oleh acara masak-memasak di televisi hanya dilakukan pada resep masakan tertentu. Promosi acara masak-memasak di televisi $\left(\mathrm{SN}_{2}\right)$ merupakan referensi yang memberikan pengaruh yang cukup besar pada ketiga kelas pendapatan untuk membeli cabai kering.

Rumah tangga pendapatan kelas 3 memiliki motivasi untuk mematuhi terbesar terhadap referensi pedagang sayuran atau supermarket yang mereka langgan $\left(\mathrm{SN}_{3}\right)$. Secara keseluruhan, rumah tangga pendapatan kelas 3 memiliki skor norma subjektif yang lebih rendah dibandingkan dengan pendapatan kelas 2 dan pendapatan kelas 3. Hal tersebut menunjukkan bahwa rumah tangga pendapatan kelas 3 mempunyai tekanan sosial yang rendah dalam pembelian cabai kering.

Skor norma subjektif yang paling rendah ditunjukkan oleh referensi iklan layanan masyarakat $\left(\mathrm{SN}_{4}\right)$. Seluruh responden setuju bahwa saat ini tidak ada imbauan dari pemerintah untuk mengkonsumsi cabai kering. Motivasi untuk mematuhi imbauan iklan layanan masyarakat lebih besar pada rumah tangga pendapatan kelas 1 dibandingkan pendapatan kelas 2 dan kelas 3 .

Sosialisasi merupakan satu upaya yang dapat meningkatkan pengetahuan konsumen tentang cabai kering. Sosialisasi yang dilakukan pemerintah secara tidak langsung akan memberikan pengaruh pada ketiga referensi lainnya untuk meningkatkan skor norma subjektif.

\section{Persepsi Pengendalian Perilaku}

Persepsi pengendalian perilaku (PBC) rumah tangga terhadap pembelian cabai kering berada pada kategori sedang, yaitu 14,80 (Tabel 4). Ketiga kelas pendapatan rumah tangga relatif memiliki skor PBC yang sama yaitu, pendapatan kelas $1(15,27)$, pendapatan kelas 2 $(13,80)$, dan pendapatan kelas $3(14,80)$.

Tabel 4. Persepsi Pengendalian Perilaku (Pembelian Cabai Kering)

\begin{tabular}{lccccccc}
\hline Rumah Tangga & $\boldsymbol{C}_{\mathbf{1}}$ & $\boldsymbol{P}_{\mathbf{1}}$ & $\mathbf{P B C}_{\mathbf{1}}$ & $\boldsymbol{C}_{\mathbf{2}}$ & $\boldsymbol{P}_{\boldsymbol{2}}$ & $\mathbf{P B C}_{\boldsymbol{2}}$ & PBC $_{\text {total }}$ \\
\hline Kelas 1 $(\mathrm{n}=11)$ & 3,00 & 1,82 & 5,55 & 3,00 & 3,27 & 9,73 & 15,27 \\
Kelas 2 $(\mathrm{n}=10)$ & 3,20 & 1,80 & 5,90 & 2,30 & 3,50 & 7,90 & 13,80 \\
Kelas 3 $(\mathrm{n}=9)$ & 3,11 & 2,11 & 6,89 & 2,33 & 3,56 & 8,44 & 15,33 \\
\hline Total $(\mathrm{n}=30)$ & 3,10 & 1,90 & 6,07 & 2,57 & 3,43 & 8,73 & 14,80 \\
\hline
\end{tabular}


Konsisten dengan sikap terhadap pembelian, rumah tangga pendapatan kelas 2 dan kelas 3 relatif tidak meyakini bahwa faktor harga cabai segar yang sangat mahal (F1) merupakan faktor yang mendorong pembelian cabai kering. Hal tersebut ditunjukkan oleh nilai $C_{2}$ (kekuatan pengendalian) yang rendah, yaitu 2,30 dan 2,33. Rumah tangga pendapatan kelas 2 dan 3 yang bersedia membeli cabai kering lebih dipengaruhi oleh kebutuhan tertentu. Sehingga pembelian cabai kering dapat dilakukan kapan saja, baik saat cabai segar harganya mahal maupun saat harga cabai segar sangat murah. Berbeda dengan rumah tangga pendapatan kelas 1 yang meyakini bahwa pembelian cabai kering didorong oleh faktor harga cabai segar yang sangat mahal $(3,00)$.

Faktor ketersediaan (F2) dianggap paling memudahkan untuk pembelian cabai kering oleh ketiga kelas pendapatan (nilai $C_{l}>3$ ). Namun saat ini ketiga kelas pendapatan tidak melihat keberadaan cabai kering di pasar atau toko sayuran terdekat. Hal ini mengakibatkan kontribusi faktor ketersediaan $\left(\mathrm{PBC}_{1}\right)$ terhadap nilai $\mathrm{PBC}_{\text {total }}$ lebih kecil daripada kontribusi faktor harga cabai yang sangat mahal $\left(\mathrm{PBC}_{2}\right)$.

Tabel 4 menunjukkan rumah tangga pendapatan kelas 3 relatif lebih mengetahui ketersediaan cabai kering saat ini, baik di pasar tradisional maupun di pasar modern. Hal tersebut ditunjukkan oleh nilai $\mathrm{P}_{1}$ sebesar 2,11. Oleh karena itu, untuk meningkatkan persepsi pengendalian perilaku diperlukan kebijakan yang mendorong ketersediaan cabai kering di pasar tradisional maupun di pasar modern.

\section{Niat Beli Cabai Kering}

Niat beli cabai kering (BI) pada ketiga kelas pendapatan rumah tangga berada pada kategori sedang, yaitu 9,67 (Tabel 5). Skor niat beli pada masingmasing kelas pendapatan berturut-turut 10,73, 9,20 dan 8,89. Hal tersebut menunjukkan bahwa niat beli cabai kering semakin turun dengan bertambahnya jumlah pendapatan rumah tangga.

Niat beli cabai kering pada rumah tangga pendapatan kelas 3 menunjukkan konsistensi dengan persepsi pengendalian perilakunya. Niat beli cabai kering lebih disebabkan oleh ketersediaan cabai daripada peningkatan harga cabai segar. Hal tersebut ditunjukkan oleh nilai $\mathrm{BI}_{3}$ $(2,44)$ yang lebih besar dari $\mathrm{BI}_{4}(2,33)$.

Upaya meningkatkan niat beli cabai kering tentu dengan meningkatkan sikap yang positif terhadap pembelian, tekanan norma subjektif, dan kekuatan faktorfaktor pendorong pembelian dalam persepsi pengendalian perilaku konsumen.

Tabel 5. Niat Beli Cabai Kering

\begin{tabular}{lccccc}
\hline \multicolumn{1}{c}{ Rumah Tangga } & $\mathbf{B I}_{\mathbf{1}}$ & $\mathbf{B I}_{\mathbf{2}}$ & $\mathbf{B I}_{\mathbf{3}}$ & $\mathbf{B I}_{\mathbf{4}}$ & $\mathbf{B I}_{\text {total }}$ \\
\hline Kelas 1 $(\mathrm{n}=11)$ & 2,45 & 2,45 & 2,82 & 3,00 & 10,73 \\
Kelas 2 $(\mathrm{n}=10)$ & 2,00 & 2,10 & 2,50 & 2,60 & 9,20 \\
Kelas 3 $(\mathrm{n}=9)$ & 1,89 & 2,22 & 2,44 & 2,33 & 8,89 \\
\hline Total $(\mathrm{n}=30)$ & 2,13 & 2,27 & 2,60 & 2,67 & 9,67 \\
\hline Sumber: data primer (2014) & & & & &
\end{tabular}


Faktor Yang Berpengaruh Terhadap Niat Beli

Berdasarkan skor rata-rata setiap variabel model TPB dan jumlah pendapatan (Lampiran 3), Persamaan regresi berganda niat beli yang diperoleh yaitu:

$$
\begin{aligned}
\hat{\mathrm{Y}}= & 1.00+0.0875 \mathrm{X} 1+0.162 \mathrm{X} 2+ \\
& 0.0213 \mathrm{X} 3-0.0187 \mathrm{X} 4
\end{aligned}
$$

Persamaan tersebut telah memenuhi asumsi Ordinary Least Square (Lampiran 4-6). Terdapat tiga atribut yang signfikan pada taraf nyata 10 persen yaitu sikap terhadap pembelian (X1), norma subjektif (X2), dan pen-dapatan rumah tangga per bulan (X4).

Nilai R-Sq sebesar 71,1 persen, artinya sebanyak 71,1 persen keragaman variabel niat beli dapat dijelaskan oleh variabel penduga dalam model, sebanyak 28,9 persen lainnya dijelaskan oleh variabel lain yang tidak dimasukkan ke dalam model.

Intrepretasi dari parameter variabel penduga yang signifikan antara lain:

1. Peningkatan 1 skor sikap terhadap pembelian cabai kering (X1)akan meningkatkan 0,0875 skor niat beli cabai kering $(\mathrm{Y})$.

2. Peningkatan 1 skor norma subjektif (X2) akan meningkatkan 0,162 skor niat beli cabai kering $(\mathrm{Y})$.

3. Setiap peningkatan pendapatan rumah tangga per bulan (X4) sebesar Rp 10.000 akan mengurangi skor niat beli cabai kering (Y) sebesar 0,0187 .

Persamaan regresi yang diperoleh menguatkan analisis deskripitif model TPB di atas. Rumah tangga pendapatan kelas 1 memiliki skor sikap pembelian terhadap cabai kering dan skor norma subjektif, yang lebih besar dibandingkan rumah tangga pendapatan kelas 2 dan 3 . Sehingga niat beli cabai kering rumah tangga pendapatan kelas 1 lebih besar dibandingkan rumah tangga pendapatan kelas 2 dan kelas 3 .

Pendapatan rumah tangga per bulan memiliki pengaruh negatif terhadap niat beli cabai kering. Semakin tinggi pendapatan rumah tangga per bulan, maka semakin rendah niatnya untuk membeli cabai kering.

\section{Elastisitas Silang}

Terdapat tiga jenis respon ibu rumah tangga terhadap peningkatan harga cabai segar. Pertama, sebanyak 7 responden (23,3 persen) tidak ingin membeli cabai kering walaupun harga cabai segar mencapai lebih dari $\mathrm{Rp}$ 100.000. Responden tersebut adalah ibu rumah tangga yang sangat mementingkan tingkat kesegaran cabai. Kedua, sebanyak 5 responden (16,7 persen) tidak terpengaruh oleh naik turunnya harga cabai segar dalam membeli cabai kering. Responden tersebut adalah ibu rumah tangga yang ingin menjaga stok persediaan cabai untuk kebutuhan tertentu, sehingga pembeliannya dilakukan kapan saja ketika stok cabai habis.

Sebanyak 18 responden (60 persen) akan mensubstitusi cabai segar menjadi cabai kering ketika terjadi peningkatan harga cabai yang signifikan. Pada saat harga cabai kering diasumsikan sebesar Rp 60.000 - 70.000, responden bersedia membeli cabai kering umumnya saat harga cabai segar sudah mencapai harga Rp 60.000. Jumlah cabai kering yang 
bersedia dibeli berkisar dari $0.1-1 \mathrm{~kg}$. Nilai elastisitas silang $\left(\mathrm{E}_{x y}\right)$ rata-rata yang diperoleh dari 60 persen responden tersebut sebesar 0,069. Nilai elastisitas tersebut menunjukkan bahwa peningkatan harga cabai segar sebesar 1 persen akan meningkatkan permintaan cabai kering sebesar 0,069 persen. Permintaan cabai kering sangat inelastis.

\section{KESIMPULAN}

Sikap konsumen rumah tangga terhadap pembelian cabai kering, persepsi pengendalian perilaku dan niat beli cabai kering berada pada batas bawah kategori sedang. Faktor yang berpengaruh nyata terhadap niat beli cabai kering pada taraf nyata 10 persen adalah norma subjektif, sikap terhadap pembelian cabai kering, dan pendapatan rumah tangga per bulan. Nilai elastisitas cabai kering terhadap cabai segar sangat inelastis yaitu sebesar 0,069 .

\section{SARAN}

1. Analisis sikap dengan pendekatan TPB tidak dapat menampilkan atributatribut produk yang menjadi prioritas konsumen. Dibutuhkan pendekatan model sikap lain untuk memperoleh informasi tersebut.

2. Penelitian lanjutan dapat melibatkan jumlah responden yang lebih banyak sehingga memperoleh hasil yang lebih representatif.

\section{UCAPAN TERIMA KASIH}

Ucapan terima kasih penulis sampaikan kepada Biro Perencanaan Kerjasama Luar Negeri, Kementerian Pendidikan dan Kebudayaan Republik
Indonesia yang telah memberikan beasiswa pendidikan (BU-BPKLN) kepada penulis selama menempuh pendidikan master di Program Studi Magister Sains Agribisnis, Institut Pertanian Bogor.

\section{DAFTAR PUSTAKA}

Ajzen I. 1991.The theory of planned behavior. Organizational Behavior and Human Decision Processes, 50, 179-211.

Awwaliyah I. 2013. Pengetahuan, sikap, dan niat beli mahasiswa terhadap makanan organik: pendekatan Theory of Planned Behavior.IPB. Bogor

[BI] Bank Indonesia. Laporan Perekonomian Indonesia 2013. Jakarta (ID): BI. [diunduh 2014 Mei 8]. Tersedia pada : www.bi.go.id

[BPS] Badan Pusat Statistik. Pengeluaran Untuk Konsumsi Penduduk Indonesia 2012. Jakarta (ID): BPS.

Dewi F, Yusalina. 2011. Aplikasi Theory of Planned Behavior pada analisis perilaku konsumen beras organik di Kota Bogor. Di dalam: [Rita N, Wahyu BP, Siti J, Popong N, Amzul R]. Prosiding Seminar Penelitian Unggulan Departemen Agribisnis. Seminar Penelitian Unggulan Departemen Agribisnis. 2011 Des 7\&14; Bogor, Indonesia. Departemen Agribisnis FEM IPB. Bogor. 
Engel JF, Blackweel RD, Miniard PW. 1994. Perilaku Konsumen Jilid I. Binarupa Aksara. Jakarta.

Izdihar H. 2013. Motivasi dan persepsi petani kentang dataran tinggi Dieng terhadap pestisida organik serta analisisnya berdasarkan Theory of Planned Behavior. IPB.Bogor.

[Kemendag] Kementerian Perdagangan Republik Indonesia. Tinjauan Pasar Cabe Edisi: Cabe/ September/2013. Jakarta (ID): Kementerian Perdagangan RI. [diunduh 2013 Nov 14]. Tersedia pada: http://ews.kemendag.go.id/publika si/PublicationView.aspx

Kotler P, Amstrong G. 2006. PrinsipPrinsip Pemasaran Jilid 1. Edisi 12.Erlangga. Jakarta.

Nurmalina R, Harmini, Koes A, Rosiana N. 2012. Analisis sikap petani terhadap atribut benih unggul jagung hibrida di Sulawesi Selatan. Di dalam: [Rita N, Netti T, Amzul R, Tintin S, Yanti NM]. Prosiding Seminar Penelitian Unggulan Departemen Agribisnis. Seminar Penelitian Unggulan Departemen Agribisnis. 2012 Des 27-28; Bogor, Indonesia. Departemen Agribisnis FEM IPB. Bogor.
[Pusdatin] Pusat Data dan Sistem Informasi Pertanian. Statistik Harga Komoditas Pertanian 2013. Jakarta (ID): Sekretariat Jenderal Kementrian Pertanian

Putri NT. 2012.Analisis pengetahuan, sikap, dan pengaruhnya terhadap pembentukan intensi dan perilaku konsumsi beras merah (Oryza nivara) mengggunakan pendekatan Theory of Planned Behavior. IPB. Bogor.

Salvatore D. 2005. Managerial Economics: Ekonomi Manajerial dalam perekonomian global. Ed ke-5. Salemba Empat. Jakarta.

Sari DR. 2013.Analisis sikap konsumen terhadap umbi-umbian sebagai alternative diversifikasi pangan (kasus di Kota Bogor, Jawa Barat).IPB. Bogor.

Sumarwan U. 2011. Perilaku Konsumen Teori dan Penerapanya dalam Pemasaran. Ghalia Indonesia. Bogor.

Thomas RL. 1997. Modern Econometrics an Intoduction. Addison Wesley. Manchester. 


\section{LAMPIRAN}

Lampiran 1. Gambar Model Theory of Planned Behavior (Ajzen 1991)

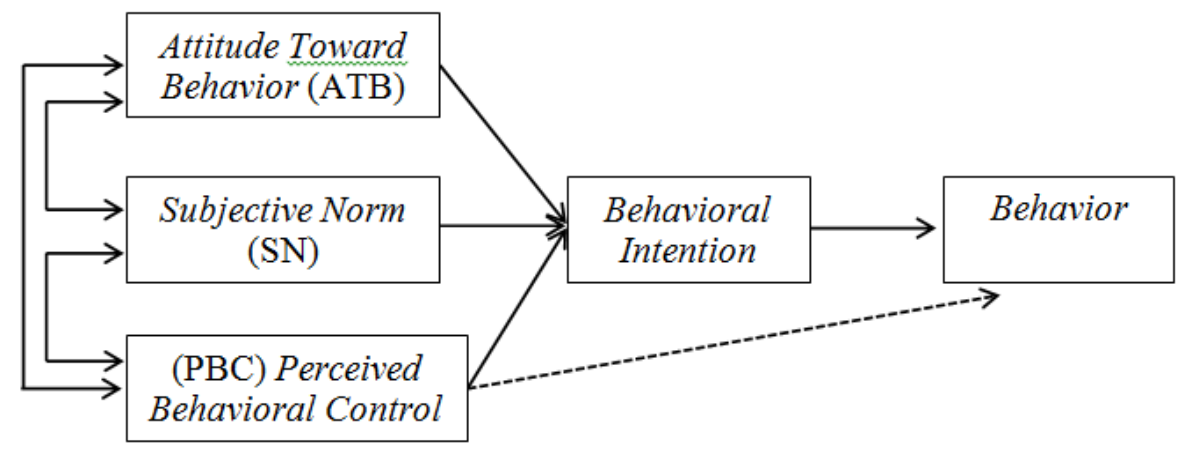

Lampiran 2. Responden penelitian

\begin{tabular}{cccccc}
\hline \multicolumn{2}{c}{ Kelas 1 } & \multicolumn{2}{c}{ Kelas 2 } & \multicolumn{2}{c}{ Kelas 3 } \\
\hline $\begin{array}{c}\text { Responden Pendapatan } \\
\text { (n) }\end{array}$ & $\begin{array}{c}\text { Responden Pendapatan } \\
\text { (n) }\end{array}$ & $\begin{array}{c}\text { Responden Pendapatan } \\
\text { (Rupiah) }\end{array}$ & $\begin{array}{c}\text { (n) } \\
\text { (Rupiah) }\end{array}$ \\
\hline 1 & 3.000 .000 & 12 & 7.000 .000 & 22 & 30.000 .000 \\
2 & 3.000 .000 & 13 & 5.000 .000 & 23 & 10.000 .000 \\
3 & 3.000 .000 & 14 & 5.500 .000 & 24 & 20.000 .000 \\
4 & 4.500 .000 & 15 & 7.000 .000 & 25 & 15.000 .000 \\
5 & 1.000 .000 & 16 & 5.000 .000 & 26 & 15.000 .000 \\
6 & 4.000 .000 & 17 & 7.100 .000 & 27 & 12.000 .000 \\
7 & 2.500 .000 & 18 & 9.000 .000 & 28 & 10.000 .000 \\
8 & 2.000 .000 & 19 & 9.500 .000 & 29 & 10.000 .000 \\
9 & 2.000 .000 & 20 & 8.000 .000 & 30 & 18.000 .000 \\
10 & 2.000 .000 & 21 & 5.500 .000 & & \\
11 & 4.000 .000 & & & & \\
\end{tabular}




\section{Lampiran 3. Skor Rata-Rata Variabel TPB}

\begin{tabular}{crrrr}
\hline Rumah tangga (n) & BI (Y) & ATB (X1) & SN (X2) & PBC (X3) \\
\hline 1 & 2,25 & 8,20 & 6,00 & 7,50 \\
2 & 3,00 & 8,40 & 6,75 & 4,50 \\
3 & 2,50 & 8,80 & 2,50 & 7,50 \\
4 & 2,75 & 9,00 & 6,75 & 10,00 \\
5 & 2,75 & 7,60 & 5,25 & 7,50 \\
6 & 3,25 & 12,20 & 6,00 & 9,00 \\
7 & 3,00 & 8,00 & 6,00 & 9,00 \\
8 & 2,75 & 9,00 & 6,00 & 7,50 \\
9 & 2,50 & 8,80 & 6,00 & 7,50 \\
10 & 2,75 & 7,20 & 5,00 & 9,00 \\
11 & 2,00 & 7,80 & 2,50 & 5,00 \\
12 & 3,00 & 5,60 & 6,00 & 6,00 \\
13 & 2,25 & 6,80 & 4,50 & 6,00 \\
14 & 2,75 & 9,80 & 3,50 & 5,50 \\
15 & 2,50 & 7,80 & 6,25 & 9,00 \\
16 & 2,25 & 9,80 & 2,00 & 12,00 \\
17 & 3,00 & 9,40 & 6,75 & 8,50 \\
18 & 1,50 & 3,40 & 1,50 & 3,50 \\
19 & 1,00 & 6,60 & 1,00 & 3,50 \\
20 & 2,25 & 7,20 & 5,75 & 9,00 \\
21 & 2,50 & 7,40 & 4,00 & 6,00 \\
22 & 1,25 & 7,60 & 1,50 & 3,50 \\
23 & 2,25 & 8,20 & 3,25 & 10,50 \\
24 & 2,75 & 7,80 & 5,25 & 16,00 \\
25 & 2,50 & 8,00 & 4,50 & 6,00 \\
26 & 1,50 & 4,60 & 2,25 & 5,50 \\
27 & 2,50 & 9,40 & 5,50 & 6,00 \\
28 & 2,75 & 8,20 & 2,50 & 5,50 \\
29 & 2,50 & 7,00 & 4,50 & 6,00 \\
30 & 2,00 & 7,80 & 3,75 & 10,00 \\
\hline & & & &
\end{tabular}




\section{Lampiran 4. Output Regresi dengan Software Minitab 14}

\section{Regression Analysis: Y versus X1, X2, X3, X4}

The regression equation is

$Y=1.00+0.0875 X 1+0.162 X 2+0.0213 X 3-0.0187 X 4$

$\begin{array}{lrrrrr}\text { Predictor } & \text { Coef } & \text { SE Coef } & \text { T } & \text { P } & \text { VIF } \\ \text { Constant } & 1.0001 & 0.3385 & 2.95 & 0.007 & \\ \text { X1 } & 0.08755 & 0.04037 & 2.17 & \underline{\mathbf{0 . 0 4 0}} & 1.3 \\ \text { X2 } & 0.16180 & 0.03917 & 4.13 & \underline{\mathbf{0 . 0 0 0}} & 1.5 \\ \text { X3 } & 0.02128 & 0.02411 & 0.88 & \underline{0.386} & 1.3 \\ \text { X4 } & -0.01872 & 0.01014 & -1.84 & \underline{\mathbf{0 . 0 7 7}} & 1.3\end{array}$

$S=0.312112 \quad R-S q=\underline{71.1 \%} \quad R-S q(\operatorname{adj})=66.4 \%$

PRESS $=3.53766 \quad$ R-Sq $($ pred $)=57.97 \%$

Analysis of Variance

\begin{tabular}{|c|c|c|c|c|c|c|c|}
\hline Source & & & DF & SS & MS & $\begin{array}{r}F \\
15 \quad 35\end{array}$ & $P$ \\
\hline Regress & ion & & 4 & 5.9813 & 1.4953 & 15.35 & \\
\hline Residua & & ror & 25 & 2.4353 & $\odot .0974$ & & \\
\hline Total & & & 29 & 8.4167 & & & \\
\hline Source & DF & Seq & SS & & & & \\
\hline X1 & 1 & 2.5 & 785 & & & & \\
\hline$X 2$ & 1 & 3.0 & 407 & & & & \\
\hline X3 & 1 & 0.0 & 305 & & & & \\
\hline X4 & 1 & 0.3 & 316 & & & & \\
\hline
\end{tabular}

Unusual Observations

$\begin{array}{lcccccc}\text { Obs } & \text { X1 } & \text { Y } & \text { Fit } & \text { SE Fit } & \text { Residual } & \text { St Resid } \\ 19 & 6.6 & 1.0000 & 1.6270 & 0.1356 & -0.6270 & -2.23 R \\ 22 & 7.6 & 1.2500 & 1.4211 & 0.2325 & -0.1711 & -0.82 \mathrm{X} \\ 24 & 7.8 & 2.750 \odot & 2.4985 & 0.2287 & 0.2515 & 1.18 \mathrm{X} \\ 28 & 8.2 & 2.7500 & 2.0523 & 0.0968 & 0.6977 & 2.35 \mathrm{R}\end{array}$

$R$ denotes an observation with a large standardized residual. $X$ denotes an observation whose $X$ value gives it large influence.

Durbin-Watson statistic $=\underline{\mathbf{2 . 0 3 0 3 8}}$ 


\section{Lampiran 5. Output Uji Glester (Deteksi Heteroskedastisitas)}

The regression equation is

C10 $=0.340-0.0050 X 1+0.0024 X 2-0.0109 \times 3-0.00026 x 4$

$\begin{array}{lrrrrr}\text { Predictor } & \text { Coef } & \text { SE Coef } & \text { T } & \text { P } & \text { VIF } \\ \text { Constant } & 0.3405 & 0.1989 & 1.71 & 0.099 & \\ \text { X1 } & -0.00501 & 0.02371 & -0.21 & 0.834 & 1.3 \\ \text { X2 } & 0.00240 & 0.02301 & 0.10 & 0.918 & 1.5 \\ \text { X3 } & -0.01094 & 0.01417 & -0.77 & 0.447 & 1.3 \\ \text { X4 } & -0.000258 & 0.005959 & -0.04 & 0.966 & 1.3\end{array}$

$S=0.183339 \quad R-S q=3.4 \% \quad R-S q(\operatorname{adj})=0.0 \%$

PRESS $=1.25044 \quad$ R-Sq $($ pred $)=0 . \odot \odot \%$

Analysis of Variance

$\begin{array}{lrrrrr}\text { Source } & \text { DF } & \text { SS } & \text { MS } & F & P \\ \text { Regression } & 4 & 0.02990 & 0.00748 & 0.22 & 0.923 \\ \text { Residual Error } & 25 & 0.84033 & 0.03361 & & \\ \text { Total } & 29 & 0.87024 & & & \end{array}$

\section{Lampiran 6. Gambar Plot Uji Normalitas}

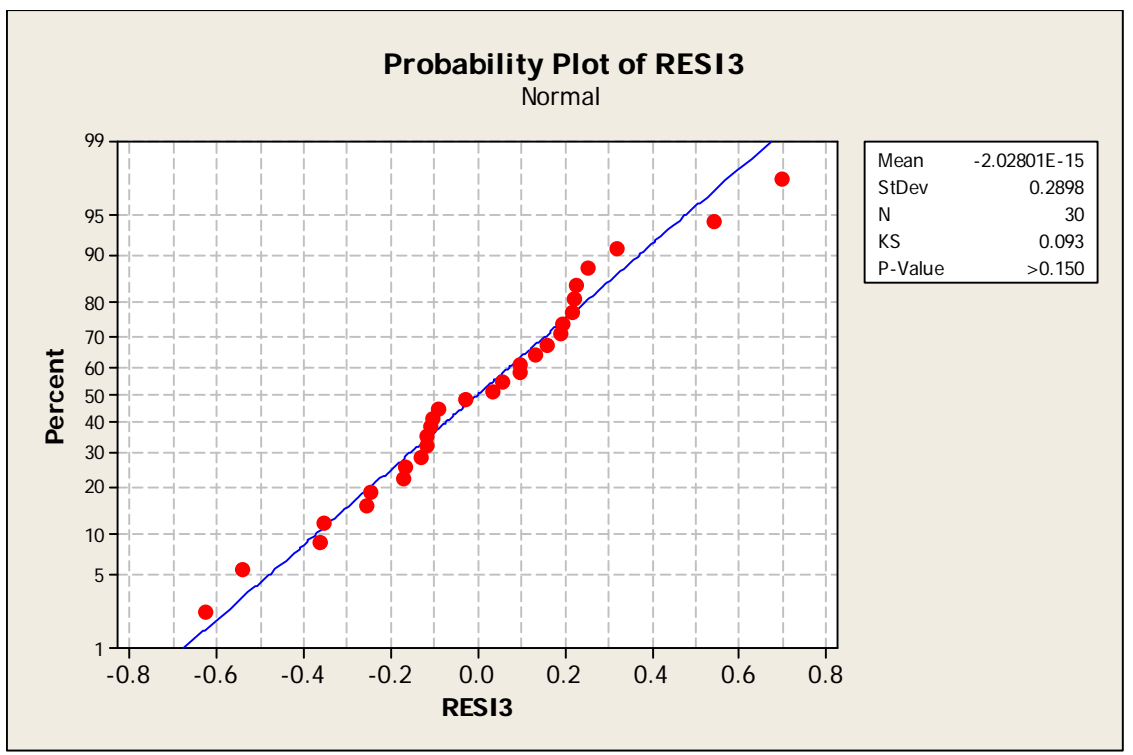

